\title{
A TECNOLOGIA E A CONSTRUÇÃO DO CONHECIMENTO CIENTÍFICO BASEADO NA ALEGORIA DA CAVERNA DE PLATÃO
}

\section{ENSAIO TÉORICO}

AMARAL, Gessyane Amorim¹, MARQUES, Lucelia das Dores², SCHWEDER, Sérgio ${ }^{3}$

AMARAL, Gessyane Amorim. MARQUES, Lucelia das Dores. SCHWEDER, Sérgio. A tecnologia e a construção do conhecimento científico baseado na alegoria da caverna de Platão. Revista Científica Multidisciplinar Núcleo do Conhecimento. Ano 06, Ed. 09, Vol. 04, pp. 101-109. Setembro de 2021. ISSN: 2448-0959, Link de acesso:

https://www.nucleodoconhecimento.com.br/educacao/conhecimentocientifico, DOI: 10.32749/nucleodoconhecimento.com.br/educacao/conhecimentocientifico

\section{RESUMO}

O presente trabalho traz em seu bojo uma reflexão acerca da alegoria da caverna de Platão e, paralelamente, descreve a sua relação com os dias atuais, através dos pressupostos da filosofia, que abarca a liberdade de pensamentos em contrapartida aos exageros do uso tecnológico, que de certo modo acorrentam os indivíduos e impedem a liberdade de desenvolvimento dos pensamentos. O objetivo é promover uma reflexão sobre o lidar com o avanço tecnológico, com sabedoria, a fim de que o homem não se torne prisioneiro dela. A metodologia utilizada foi a bibliográfica. A partir dessa pesquisa, concluímos que, atualmente o consumo de informações é grande, tornando o excesso de conhecimento volátil. Dessa forma, é necessário identificar o que é ideal, real e ideológico, de modo a desenvolver uma relação com o que já se tem, aliando o conhecimento de si sob à luz da filosofia.

\footnotetext{
${ }^{1}$ Pós-graduação educação, Graduação em Pedagogia

2 Pós-graduação educação, Graduação em Pedagogia.

${ }^{3}$ Orientador
}

RC: 97293

Disponível em: https://www.nucleodoconhecimento.com.br/educacao/conhecimentocientifico 
Palavras-Chave: Platão, Filosofia, Conhecimento científico.

\section{INTRODUÇÃO}

$\mathrm{Na}$ História da Filosofia, desde a antiguidade, diversos pensadores arquitetaram diálogos, discursos, sumas, investigações e outras formas de produção filosófica para elucidar a essência da realidade. Nesse sentido, a filosofia platônica, em vários aspectos, se faz presente e atual, seja no viés psicológico, pedagógico, antropológico, filosófico, sociológico e organizacional, sendo possível interpretar a alegoria da Caverna de diferentes formas e elucidar a relação de apropriação do conhecimento verdadeiro.

Gomes (2008), ao citar Platão, retrata que a caverna era um símbolo do mundo antigo, que está em continuidade na era atual. Enquanto, as correntes, tinham significados de ignorância que subordinavam aos povos, as quais têm possíveis interpretações relacionadas a culturas, crenças, e o bom senso, que são compreendidos no decorrer da vida. Sendo assim, a complexidade presente e a gravidade de seus efeitos, denotam a urgência de uma reformulação nos processos e propósitos do ser humano que a sociedade pretende formar.

Diante dessa perspectiva, o presente trabalho, tem como fundamento uma crítica ao uso exagerado de meios tecnológicos como facilitador no processo de aprendizagem e a influência deste sobre o pensamento humano, estabelecendo uma ligação entre a alegoria da Caverna de Platão e os dias atuais, retratando a chamada caverna tecnológica.

O presente trabalho, é norteado no fundamento da correspondência entre Filosofia, a busca pelo conhecimento e as possibilidades de crescimento intelectual. A finalidade do exposto visa buscar o entendimento sobre o consumismo tecnológico e sua influência durante o processo de aprendizagem, a qual tem influência negativa para o desenvolvimento do saber filosófico.

RC: 97293

Disponível em: https://www.nucleodoconhecimento.com.br/educacao/conhecimentocientifico 
Morin (2000, p. 41) retrata que "os saberes, são até hoje, de modo geral, na escola, pré-selecionados e passados prontos, mesmo, se falando tanto, que a mente não é uma folha em branco". Disso, depreende-se que, atualmente, o consumo exacerbado da informação rápidas e passageiras raramente tem se transformado em conhecimento, sendo este excesso, algo de pouco valor. Destarte, o aprendizado acabou perdendo seu lugar para a informação que já tem um foco exclusivo, se tornando um meio de entretenimento.

Nesse contexto, a tecnologia, se constitui em uma ferramenta que, aparentemente, se tornou intrínseca à vida das pessoas e está em crescente avanço e modificação a todo tempo, em todos os ramos e setores da sociedade. A proposta da discussão deste trabalho, visa buscar reflexões sobre o homem contemporâneo na era tecnológica e como ele pode lidar com isto sem se tornar escravo deste.

Platão, ao apresentar a alegoria da Caverna, demonstra a importância do conhecimento filosófico e da educação como superação da ignorância. Sendo possível, portanto, realizar um paralelo entre a sociedade contemporânea e esta alegoria.

A existência, na era tecnológica, está interligada ao imaginário, as exibições televisivas, redes sociais, jogos eletrônicos etc., os quais retiram os indivíduos da realidade, imprimindo conceitos do que é perfeito. Na teoria de Platão, as atrações, evidenciam o consumismo exagerado e a aparente necessidade de se ter uma infinidade de coisas para satisfazer o ego. Paralelamente a isto, de acordo com Platão, os sujeitos estão presos nesta realidade imaginada, acreditando que são retratações do mundo, ocasionando a alienação (GOMES, 2008). A evolução da tecnologia, ainda que muito importante, margina o homem da realidade e $\mathrm{o}$ afasta do convívio pessoal, levando-o ao isolamento e a não querer o entendimento, o conhecimento.

A facilidade que a tecnologia e as inovações tecnológicas trazem são grandes desafios para a filosofia contemporânea, em especial a Filosofia na Educação, pois

RC: 97293

Disponível em: https://www.nucleodoconhecimento.com.br/educacao/conhecimentocientifico 
esta tem de encontrar meios para "alfabetizar" o saber virtual e tecnológico, que a nova geração tanto admira. (GOMES, 2008, p. 52)

Tais considerações, inspiram a busca por recursos que favoreçam o ensino e a aprendizagem da Filosofia com um sentido real, na recusa ao tratamento meramente histórico de temas e problemas cruciais, tendo em vista seu potencial formador e transformador dos seres humanos.

\section{A ALEGORIA DA CAVERNA DE PLATÃO}

O mito da caverna de Platão, traz em sua tônica o tripé formado pela educação, linguagem e teoria do conhecimento, com vistas à constituição do estado ideal (CHAUÍ, 2002). No entanto, atualmente, essa alegoria pode ser utilizada para resgatar os ensinamentos de Platão, de forma a compreender o poder exercido pelos meios tecnológicos em geral, sobre as opiniões da sociedade contemporânea.

A alegoria da caverna, cita a condição de vida dos prisioneiros, que se encontram acorrentados e condicionados, a pouca mobilidade. A entrada na caverna, permitia que a luz de uma fogueira, situada de forma estratégica, criasse reflexos de sujeitos se movimentando e de seus utensílios, por meio de uma projeção da sombra nas paredes dentro da caverna. Nessas condições, os prisioneiros, jamais viram as pessoas e utensílios da forma como são na realidade, o que acarretou a crença de que as sobras fossem de fato a realidade presente fora da caverna. Para Platão (427-347 a.c), "a caverna é o mundo em que vivemos, e as sombras, o modo como enxergamos tudo". (GOMES, 2008)

Destarte, Platão se utiliza da alegoria da representação da caverna para demonstrar que o mundo, como o compreendemos, utiliza-se de sentidos próprios, sendo ilusório e confuso. Somente no âmbito espiritual, está o que de fato é real, isto é, as ideias, as quais são desconhecidas para aqueles que se encontram na caverna, sendo percebidos apenas pelos filósofos.

RC: 97293

Disponível em: https://www.nucleodoconhecimento.com.br/educacao/conhecimentocientifico 
Mas, nem sempre é fácil sair da caverna. Em consonância, Saramago (2002) nos recorda a respeito do conceito do que é contrário daquilo que é unicamente material. Retratando que os humanos não devem ser manipulados, pois se comparados a um material imóvel, se diferem das pessoas, porque elas, em sua essência refletem, fazem questionamentos e agem. Por outro lado, se apresenta a fragilidade do humano frente a princípios que demandam do seu domínio.

Exposto assim, desarmado, com a cabeça caída para trás, a boca meio aberta, perdido em si mesmo, apresentava a imagem pungente de um abandono sem salvação, como um saco que se tivesse rompido e deixado escoar pelo caminho o que levava dentro. (SARAMAGO, 2010, p. 41).

Por fim, Platão ressalta que o sujeito que tem curiosidade é estimulado a sair da caverna e ver o mundo em sua realidade, ou seja, do lado de fora de caverna. Neste sentido, ação de sair da caverna, simboliza encarar o sistema alienado e de medo, pois quando preso à caverna o homem tendo a se desligar do mundo real. Com isso, ao ser estimulado a sair da caverna, o homem é incitado a caminhar por distintos caminhos, é levado a desvendar o desconhecido, a excluir da própria consciência aquilo que o deixa inseguro e ao desenvolvimento de um senso crítico, visto que é indispensável que o sujeito seja livre para se opor ou concordar com o outro. O viver no mundo real cria possibilidades de se desprender do egoísmo encontrado nas culturas sociais. (SARAMAGO, 2010).

\section{A AUSÊNCIA DO CONHECIMENTO E A INÉRCIA DO DESENVOLVIMENTO INTELECTUAL}

O conhecimento científico é uma conquista inerente ao ser humano a partir de suas buscas. A revolução científica do século XVII simboliza a introdução da ciência, para um diálogo com o senso comum e a reflexão filosófica. Ou seja, pelo conhecimento o homem penetra as diversas áreas da realidade para dela tomar posse (DEMO, 2000)

Demo (2000) ainda destaca que é preciso dominar a capacidade de "aprender a aprender" e saber pensar, para, dessa forma, questionar aquilo que é imposto como

RC: 97293

Disponível em: https://www.nucleodoconhecimento.com.br/educacao/conhecimentocientifico 
verdade. Para complementar, Saramago (2010) relata que o "preso" ao sair da caverna está procurando a essência de sua existência, o que o leva a buscar um real conhecimento, não estando satisfeito com o que a vida dele foi até ali. Logo, é preciso destacar a característica que distingue o homem dos outros animais, que é a busca contínua por melhorias do mundo que o cerca, ou seja, não há conformidade com a realidade vivida, havendo uma constante busca pelo conhecimento.

Todavia, é preciso velar pela ciência, que consiste no conhecimento racional das essências, das ideias imutáveis, objetivas e universais. Para isso, Platão destaca as ciências como a matemática, a geometria e a astronomia, pois são consideradas por ele, atalhos necessários a serem percorridos pelo pensador, até o ápice da reflexão filosófica que é a descoberta e si.

Por isso, a filosofia procura compreender a realidade em seu contexto mais universal. Não trazendo soluções definitivas para as questões, mas sim orientando o homem, no que tange à utilização de suas habilidades, para a concretização de um melhor sentido para sua vida (CHAUÍ, 2002).

Nesse sentido, Vernant (1996) nos orienta que sobre a possibilidade de procurar pelo desconhecido e assegurar o coletivo na sociedade. Até hoje, quem possui o poder provoca insegurança, no sentido de amedrontar os outros, com a finalidade de mantê-los sobre seus domínios. Para eles, é muito prático a grande maioria ser "massa de manobra" de outrem, pois, ao serem dominados, a massa, não realiza mais questionamentos, acatam o que thes é imposto e assim se asseguram a opressão do sistema. Portanto, a ausência do conhecimento promove na sociedade o alienamento, o que acaba por aprisionar a "massa" em "novas prisões". Tais movimentos podem ser entendidos como as "cavernas atuais", que retratam a alegoria de Platão na pós-modernidade. Simplificando, também, locais privados onde pessoas se refugiam da convivência em sociedade, se negando a buscar o novo.

RC: 97293

Disponível em: https://www.nucleodoconhecimento.com.br/educacao/conhecimentocientifico 
Dessa forma, entende-se que tais "prisões pós-modernas" mantém a mente e espírito oprimidos e que acabam se manifestando na sociedade por uma sequência de alienações e desrespeito aos direitos fundamentais. Além de provocar o esquecimento social, como será abordado a seguir.

\section{A CAVERNA PÓS-MODERNA}

A pós-modernidade, traz em seu bojo, através do famigerado capitalismo, um sentimento de incerteza e angústia, percebidas no semblante humano, diante deste novo mundo baseado na racionalidade extrema. Diante deste cenário extremamente influenciado pela globalização, pelo excesso de informação e, sobretudo, pela tecnologia, o homem acabou por se apropriar de uma nova forma de cultura, ou seja, do conhecimento fútil e descartável, que não será base para a construção do seu conhecimento científico (SARAMAGO, 2010).

Saramago (2010, p. 41), faz um paralelo sobre a alegoria da caverna de Platão com a sociedade contemporânea. Segundo o escritor, "as pessoas vivem em uma grande caverna, seus desejos são movidos por sombras, essas sombras são ideologias que as alimentam todos os dias, mantendo-as afastadas do poder." Com isso, o autor nos remete a uma visão muito pessimista desta sociedade pós-moderna, de atitudes estéreis e vazias, deixando claro que toda expressão de liberdade demonstrada por ela se traduz em sinais de pura escravidão.

\section{CONSIDERAÇÕES FINAIS}

A alegoria da Caverna de Platão se constitui em um permanente convite à reflexão, pois, é através dela, que se pode ir em busca de valores importantes para o estudo da filosofia, auxiliando na construção do senso crítico.

Diante do exposto é possível a reflexão de que a informação passou a ocupar o espaço do aprendizado, estando, quase sempre, focalizada exclusivamente no entretenimento. $O$ homem se priva da construção de seu conhecimento, pois 
enquanto pensa que aprende e com a tecnologia, esta o domina. Esse movimento cria uma dependência no ser humano, que vai aumentando a partir da falta de consciência dos males que a" "caverna digital" pode resultar.

Ultimamente, percebe-se uma grande mudança nos hábitos das pessoas. Isso se deve ao sensacionalismo das redes sociais, onde os programas tradicionalmente cumpridos foram deixados de lado em troca de passar horas navegando na internet, em suas cavernas digitais.

Destarte, a facilidade que a tecnologia e suas inovações trazem é um grande desafio para a filosofia contemporânea. Neste contexto, surge a filosofia da educação, a qual se incube de mudar o foco do saber virtual e tecnológico que a sociedade moderna utiliza como forma de poder.

Contudo, observa-se que o mau uso da tecnologia tende a gerar um grupo de indivíduos incapazes de pensar por si mesmos, de empatizar e estabelecer relações com os outros. Com isso, é facilmente observada a redução da capacidade linguística e argumentativa, mesmo em simples conversas. Nestes casos, o que interessa é transmitir a mensagem, não a enriquecer com expressões ou com argumentos de forma a defender uma ideia.

Importante e necessário é que se distinga de fato o que atualmente é real, ideal e ideológico, buscando o conhecimento e estabelecendo uma relação com o que já se possui, aprendendo a raciocinar por si próprio à luz da filosofia.

Tentando encontrar uma saída para essa situação, sugere-se a cisão das propostas anteriormente comentadas, por estarem na origem do problema e exigirem uma resposta para ele, sob pena de dar razão a Platão quando nos apresenta a ideia de que seriam necessários cinquenta anos para se fazer um homem, que possua maturidade plena, aliada à descoberta do conhecimento através de seu significado existencial. 
Portanto, é necessário questionar, criticar e duvidar sempre. Esse é o método mais prático trazido por Platão e que poderá evitar a manipulação pelos detentores dos mais diversos tipos de poder.

\section{REFERÊNCIAS}

CHAUI, Marilena. Introdução à história da filosofia: do pré-socrático a Aristóteles. 2. ed. São Paulo: Companhia das Letras, 2002.

DEMO, Pedro. Conhecer \& Aprender - Sabedoria dos limites e desafios. Porto Alegre: ARTMED, 2000.

GOMES, Morgana. Coleção lluminados da Humanidade no17: Platão. 1ed. SÃO PAULO, 2008.

MORIN; Edgar. Os Sete Saberes necessários à Educação do Futuro. $8^{\text {a }}$ Edição Cortez Editora, edição Brasileira, São Paulo, 2000.

SARAMAGO, J.S. A Caverna. Companhia da Letras, São Paulo, 2010.

VERNANT, Jean-Pierre. As origens do pensamento grego. Trad. Isis B. da Fonseca 9aㅡ ed. Rio de Janeiro: Bertrand do Brasil, 1996.

Enviado: Maio, 2021.

Aprovado: Setembro, 2021.

RC: 97293

Disponível em: https://www.nucleodoconhecimento.com.br/educacao/conhecimentocientifico 